\title{
IPTU X ITR: conflito entre os critérios espaciais
}

\author{
IPTU X ITR: conflict between the spatial criteria
}

\author{
Lisandra Cristina Calvo Necchi \\ Loreanne Manuella de Castro França \\ João Carlos L. Santini ${ }^{1}$
}

\begin{abstract}
Resumo
0 presente artigo procura elucidar questões não claras a respeito da hodierna controversa referente à incidência de Imposto Predial Territorial Urbano (IPTU) ou Imposto Territorial Rural (ITR) quanto à local ização e ao fim econômico que o imóvel objeto de incidência de tributação apresenta. Busca-se, após breves considerações acerca das regras-matrizes de cada imposto, apresentar 0 entendimento majoritariamente adotado tanto pela doutrina quanto pelos tribunais brasileiros.
\end{abstract}

Palavras Chave: IPTU; ITR; Critério Espacial; Localização; Destinação econômica.

\begin{abstract}
This article seeks to clarify unclear questions today about the controversy regarding the incidence of Territorial Urban property tax (property tax) or the Rural Territorial Tax (ITR) and the location and economic order that the property subject to taxation incidence of presents. The aim is, after brief remarks about the rules of each taxarrays, present understanding mainly adopted both by doctrine and by the Brazilian courts.
\end{abstract}

Keywords: First Property tax; ITR; Criterion Space, location, economic Destination.

\section{Introdução}

Após turbulento período jurisprudencial acerca do exame de constitucionalidade dos seguidos instrumentos normativos promulgados ao longo dos últimos 40 anos, finalmente, pode-se dizer, que os doutrinadores e os tribunais brasileiros parecem caminhar em um único caminho, qual seja, o de se dar preferência à destinação econômica do imóvel objeto de tributo.

Em relação à essa sucessão de interpretações normativas, oportuno e importante

\footnotetext{
${ }^{1}$ Todos os autores são acadêmicos do 5o Ano do Curso de Direito da Universidade Estadual de Londrina.
}

Revista de DiReito Público, LondRina, V. 4, N. 1. P. 125-139, Jan/ABR. 2009. 
ressaltar que, ao ser promulgado, o Código Tributário Nacional (CTN) valeu-se do critério topográfico para delimitar o fato gerador do Imposto sobre a Propriedade Predial e Territorial Urbana (IPTU) e o Imposto sobre a Propriedade Territorial Rural (ITR): se o imóvel estivesse situado na zona urbana, incidiria o IPTU; se na zona rural, incidiria o ITR.

Ocorre que, antes mesmo da entrada em vigor do CTN, o Decreto-Lei (DL) no 57/66 alterou esse critério, estabelecendo estarem sujeitos à incidência do ITR os imóveis situados na zona rural quando utilizados em exploração vegetal, agrícola, pecuária ou agro-industrial.

Na seqüência, a jurisprudência reconheceu validade ao DL 57/66, para, ao decorrer dos anos vindouros, navegar de forma instável na interpretação, não só desse, mas de outras normas que se seguiram ao referido Decreto-lei.

Melhor explanada ao longo do artigo, de antemão pode-se dizer que tal evolução interpretativa é fruto dos seguidos estudos promovidos sob um olhar especialmente voltado para a análise das regras-matrizes dos citados impostos.

Seguem, assim, as referidas análises pontuais para, em um segundo momento, adentrar-se no cerne da celeuma tratada no presente artigo, qual seja, a discussão acerca da incidência de IPTU ou ITR em determinados imóveis.

\section{Regra-matriz do IPTU}

Paulo de Barros Carvalho nos ensina que a estrutura da regra-matriz é composta pela hipótese tributária e fato jurídico tributário, que comporiam o antecedente da regramatriz e o conseqüente da norma e as relações jurídicas tributárias, que comporiam o conseqüente da regra-matriz. Os critérios da hipótese são: 0 material, 0 espacial e 0 temporal; os do conseqüente são o critério quantitativo e o pessoal. (CARVALHO, 2004, p.244-245).

Os artigos 156, da Constituição Federal (CF) e 32 a 34 do CTN, trazem os dados gerais para a construção da regra-matriz de incidência do IPTU. Seguem os mesmos:

Art. 156, CF: Compete aos Municípios instituir impostos sobre: I - propriedade predial e territorial urbana;

(...)

$\S 1$ Sem prejuízo da progressividade no tempo a que se refere 0 artigo 182, §4, inciso II, o imposto previsto no inciso I poderá:

I - ser progressivo em razão do valor do imóvel; e

II - ter alíquotas diferentes de acordo com a localização e o uso do imóvel. (...) 
Art. 32, CTN. 0 imposto, de competência dos Municípios, sobre a propriedade predial e territorial urbana tem como fato gerador a propriedade, o domínio útil ou a posse de bem imóvel por natureza ou por acessão física, como definido na lei civil, localizado na zona urbana do M unicípio.

$\S 1$. Para os efeitos deste imposto, entende- se como zona urbana a definida em lei municipal, observado o requisito mínimo de existência de melhoramentos indicados em pelo menos dois dos incisos seguintes, construídos ou mantidos pelo Poder Público:

I - meio-fio ou calçamento, com canalização de águas pluviais; II - abastecimento de água;

III - sistema de esgotos sanitários;

IV - rede de iluminação pública, com ou sem posteamento para distribuição domiciliar;

V - escola primária ou posto de saúde a uma distância máxima de três quilômetros do imóvel considerado.

§2‥ A lei municipal pode considerar urbanas as áreas urbanizáveis, ou de expansão urbana, constantes de loteamentos aprovados pelos órgãos competentes, destinados à habitação, à indústria ou ao comércio, mesmo que localizados fora das zonas definidas nos termos do parágrafo anterior.

Art. 33, CTN. A base do cálculo do imposto é o valor venal do imóvel.

Parágrafo único. Na determinação da base de cálculo, não se considera o valor dos bens móveis mantidos, em caráter permanente ou temporário, no imóvel, para efeito de sua utilização, exploração, aformoseamento ou comodidade.

Art. 34, CTN. Contribuinte do imposto é o proprietário do imóvel, o titular do seu domínio útil, ou o seu possuidor a qual quer título.

Desta forma, tem-se que, no caso do imposto predial e territorial urbano, os critérios da hipótese tributária são os seguintes:

- Critério material (a conduta desejada): ser proprietário de imóvel predial ou territorial urbano, titular de seu domínio útil, ou seu possuidor a qualquer título;

- Critério espacial (local para a ocorrência do fato jurídico): o imóvel deve estar localizado na zona urbana do município;

- Critério temporal (assinala o surgimento de um direito subjetivo para o ente e de um dever jurídico para o sujeito passivo): via de regra, em 1 으 de janeiro do ano civil; - Critério pessoal (aponta os sujeitos da relação): sujeito ativo - Municípios, Distrito Federal e Território sem municípios (acaso existam); e sujeito passivo - qualquer pessoa, física ou jurídica, que seja proprietária plena do bem predial ou territorial, ou, quem tenha domínio útil ou qualquer tipo de posse com ânimo, exercício ou exteriorização de tornar-se proprietário pleno. (MIRANDA, 2003, p. 320-321);

- Critério quantitativo (exprime o valor pecuniário da dívida): composto pela 
base de cálculo e alíquota. A base de cálculo é o valor venal do imóvel, sendo que a alíquota varia de município para município e de acordo com a utilização, pelo mesmo, do princípio da progressividade.

Apesar dos critérios estarem estabelecidos em lei, não há entendimento pacifico na doutrina e jurisprudência sobre o alcance de alguns termos e dispositivos da lei. Existem divergências em vários critérios da regra-matriz de incidência do IPTU, o presente estudo foca-se na problemática do critério espacial, a qual abordar-se-á posteriormente.

\section{Regra-matriz do ITR}

A competência para instituir o imposto territorial rural é da União (Art.153, VI da CF), contudo o município pode fiscalizar e cobrar o ITR em seu território, desde que celebrado convênio e desde que isso não acarrete redução do imposto ou qualquer outra forma de renúncia fiscal (de acordo com a Lei $\mathrm{n}$ 0 11.250/2005).

Dispõe o Art. 153 da CF:

Art. 153. Compete à União instituir impostos

sobre: (...)

$\mathrm{VI}$ - propriedade territorial

rural; (...)

$\S 4$ 4․ 0 imposto previsto no inciso VI do caput: I - será progressivo e terá suas alíquotas fixadas de forma a desestimular a manutenção de propriedades improdutivas; II - não incidirá sobre pequenas glebas rurais, definidas em lei, quando as explore o proprietário que não possua outro imóvel;

III - será fiscalizado e cobrado pelos M unicípios que assim optarem, na forma da lei, desde que não implique redução do imposto ou qualquer outra forma de renúncia fiscal. (Incluído pela Emenda Constitucional nํ 42, de 19.12.2003)

(...)

A Lei $n^{0}$ 11.250/2005 estabelece:

Art.1‥ A União, por intermédio da Secretaria da Receita Federal, para fins do disposto no inciso III do $\S 40$ do art. 153 da Constituição Federal, poderá celebrar convênios com o Distrito Federal e os Municípios que assim optarem, visando a delegar as atribuições de fiscalização, inclusive a de lançamento dos créditos tributários, e de cobrança do Imposto sobre a Propriedade Territorial Rural, de que trata 0 inciso VI do art. 153 da Constituição Federal, sem prejuízo da competência supletiva da Secretaria da Receita Federal.

$\S 1$ 1․ Para fins do disposto no caput deste artigo, deverá ser observada a legislação federal de regência do Imposto sobre a Propriedade Territorial Rural.

$\S 2$ 2‥ A opção de que trata o caput deste artigo não poderá implicar redução do imposto ou qualquer outra forma de renúncia fiscal.

(...) 
O ITR está previsto no art. 29 do Código Tributário Nacional:

Art. 29, CTN. 0 imposto, de competência da União, sobre a propriedade territorial rural tem como fato gerador a propriedade, o domínio útil ou a posse de imóvel por natureza, como definido na lei civil, localizado fora da zona urbana do M unicípio.

O conceito de zona urbana, por sua vez, está contido no artigo 32 , §§ $1^{\circ}$ e 20 do CTN, a partir do qual, residualmente, pode-se extrair o conceito de zona rural. Como já exposto anteriormente, restando compreendida como zona rural aquela que não for delimitada pelo Município como zona urbana.

Pode-se sintetizar a regra-matriz do ITR da seguinte maneira:

- Critério material: Ser proprietário, possuir domínio útil ou posse da terra (com ânimo de ser proprietário);

- Critério espacial (local para a ocorrência do fato jurídico): 0 imóvel deve estar localizado na zona rural, conceito dado por meio de exclusão, ou seja, compreende zona rural o que não for definida por lei municipal como zona urbana;

- Critério temporal: via de regra, em 10 de janeiro do ano civil;

- Critério pessoal: sujeito ativo - via de regra é a União, que tem competência tributária plena (instituir, arrecadar e fiscalizar), sendo que $50 \%$ são repassados ao Município relativamente aos imóveis neles situados (art. 158, II, CF). Em caso de convênios, Município e Distrito Federal podem fiscalizar e cobrar (art. 153, §4으, III da CF); sujeito passivo - qualquer pessoa que seja proprietária plena do bem imóvel rural, ou, quem tenha domínio útil ou qualquer tipo de posse com ânimo, exercício ou exteriorização de tornar-se proprietário pleno.

- Critério quantitativo: Base de Cálculo - a base de cálculo é o valor fundiário do imóvel rural, o chamado valor da terra nua. Seria o valor do imóvel, menos construções, culturas, pastagens, florestas plantadas; (VTNt =VTN x área tributável; área total). Alíquota área total cruzada com o grau de utilização. (Imposto devido =VTNt x Alíquota, área total do imóvel em hectares e alíquotas progressivas em porcentagem).

0 princípio da progressividade também é aplicado ao ITR, que possui alíquotas fixadas de forma a desestimular a manutenção de propriedade improdutivas, não incidindo sobre pequenas glebas rurais, definidas em lei, quando as explore, só ou com sua família, o 
proprietário que não possua outro imóvel (art. 153, §4, CF).

Quanto às imunidades e isenções, ambas estão regulamentadas no Decreto no 4.382/2002 - lembrando-se que imunidade é a dispensa constitucional do pagamento do tributo, enquanto isenção, por sua vez, é a dispensa legal do pagamento do tributo.

Algumas imunidades:a pequena gleba rural, desde que o seu proprietário a explore só ou com sua família, e não possua outro imóvel (art. 3ำ, I); os imóveis rurais da União, dos Estados, do Distrito Federal e dos M unicípios (art. 3o, II); e os imóveis rurais de autarquias e fundações instituídas e mantidas pelo Poder Público, desde que vinculados às suas finalidades essenciais ou às delas decorrentes (art. $3^{\circ}$, III)

Por fim, algumas isenções: o imóvel rural compreendido em programa oficial de reforma agrária, caracterizado pelas autoridades competentes como assentamento, que, cumulativamente seja explorado por associação ou cooperativa de produção; que a fração ideal por família assentada não ultrapasse os limites da pequena gleba rural e que 0 assentado não possua outro imóvel (art. 4ํ, I).

\section{Breves considerações sobre o critério espacial do IPTU}

Conforme já visto e de acordo com a teoria de Paulo de Barros Carvalho, a regramatriz de incidência tributária é composta pela hipótese tributária e pela relação jurídica tributária.

Compõem a relação jurídica tributária o critério pessoal - traduzido no sujeito ativo e no sujeito passivo - e o critério quantitativo - no qual se inclui a base de cálculo e a alíquota.

Por outro lado, a hipótese tributária tem o critério material - comportamentos de pessoas que encerram um fazer, um ser ou um dar, os quais são sempre formados por um verbo e seu complemento -, o critério temporal - instante em que ocorre o critério material da hipótese tributária, ou, dito de uma maneira mais simples e até mesmo equivocada, o momento que acontece o fato gerador - e o critério espacial - local onde ocorreu o critério material da hipótese tributária, o locus facti.

É nesse último critério (critério espacial) que se dará mais ênfase no trato dos conflitos relacionados ao Imposto sobre a Propriedade Predial e Territorial Urbana - IPTU e o Imposto sobre a Propriedade Territorial Rural - ITR, principalmente em razão dos conflitos 
relacionados à conceituação da expressão "zona urbana".

Desse modo, constata-se que o critério espacial do IPTU é o perímetro urbano do M unicípio sujeito ativo. Contudo, em razão da corrente expansão da zona urbana, observase uma dificuldade com relação ao conceito da mesma, o qual vem ganhando novas delimitações.

Da análise do parágrafo primeiro do artigo 32 do Código Tributário Nacional, emerge que o município tem autonomia para definir os limites da zona urbana em legislação específica, obedecendo-se ao requisito mínimo de se ter no local pelo menos dois dos melhoramentos dispostos nos incisos, quais sejam: meio-fio ou calçamento com canalização de águas pluviais; abastecimento de água; sistema de esgotos sanitários; rede de iluminação pública, com ou sem postes para distribuição aos domićilios; e escola primária ou posto de saúde a uma distância máxima de três quilômetros do local.

Contudo, de outro vértice, verifica-se que o Estatuto da Terra e, posteriormente, a Lei no 8.629/93 - que disciplina os dispositivos constitucionais que se relacionam com a reforma agrária - em seu art. 4ํ, aplica o critério da destinação do imóvel para se definir se é urbano ou rural. Isto significa dizer que, seria urbano o imóvel destinado a moradia, comércio ou indústria, e rural o destinado a atividade agropecuária.

Porém, é válida a observação de que o Código Tributário Nacional, ao revestir o M unicípio da competência para delimitar a zona urbana, o fez em consonância com 0 artigo 182 da Constituição Federal, o qual estabelece que esse ente da Federação é o responsável por instituir a política de desenvolvimento urbano, através de seu Plano Diretor, a fim de que a propriedade urbana cumpra sua função social. Além disso, se fosse adotado o critério da destinação do imóvel para se diferenciar zona urbana de zona rural, o M unicípio restaria impossibilitado de ordenar o desenvolvimento pleno das funções sociais da cidade, posto que os limites entre zona rural e zona urbana seriam desaparecidos, e poderia haver, no território municipal, imóveis urbanos e rurais de forma intercalada.

Por esta razão, afirma-se que qualquer aplicação divergente da estabelecida no Código Tributário Nacional fere o princípio da autonomia dos municípios.

Também, é importante mencionar acerca da declaração de inconstitucionalidade, pelo Supremo Tribunal Federal (RE 93.850-8 MG), do artigo 60 e seu parágrafo único da Lei no 5.868/72, a qual cria o Sistema Nacional de Cadastro Rural. 
Tal artigo, em seu caput, utilizava o critério da destinação do imóvel para definir o que era imóvel rural, para efeito de incidência do Imposto sobre a Propriedade Territorial Rural, dizendo que "considera-se imóvel rural aquele que se destinar à exploração agrícola, pecuária, extrativa vegetal ou agroindustrial e que, independentemente de sua localização, tiver área superior a 1 (um) hectare". Em seu parágrafo único, dispunha que estariam sujeitos ao Imposto sobre a Propriedade Predial e Territorial Urbana todos os imóveis que não se enquadrassem no estabelecido no já comentado caput.

Então, entendeu o STF que a fixação do critério para se definir imóvel urbano e rural é matéria inserida no Código Tributário Nacional, que define as normas gerais da tributação, motivo pelo qual somente poderia ser revogada por lei complementar.

Ademais, é um faculdade dos Municípios (art. 32, §2ํㅡㄴ CTN) considerar como urbana a zona urbanizável e a de expansão urbana.

Segundo Sérgio Villaça, as zonas de expansão urbana devem ser tratadas como uma espécie de medida da expansão da população, posto que futuramente serão transformadas em novos bairros do M unicípio (VILLAÇA, 2008, p. 02). E é por este mesmo motivo que já estão sujeitas a tributação (incidência de IPTU), as limitações ao direito de construir e ao cumprimento de função social.

Já as zonas urbanizáveis são aquelas que, mesmo fora do perímetro urbano, são programadas para realizar atividade urbana por excelência, característica que a sujeita às regras do Direito Urbanístico e, conseqüentemente, do Direito Tributário, fazendo incidir IPTU sobre os imóveis nela situados (VILLAÇA, 2008, p. 03).

Neste ponto, interessante explicar a maneira definida no Município de Londrina, sobre o qual se realizou a pesquisa de campo para elaboração do presente artigo científico.

Assim dispõe o artigo 164 do Código Tributário Municipal - Lei no 7.303 de 30 de dezembro de 1997:

Art. 164, CTN. 0 Imposto sobre a Propriedade Predial e Territorial Urbana tem como fato gerador a propriedade, o domínio útil ou a posse do bem imóvel, por natureza ou por acessão física como definida na lei civil, construído ou não, localizado na zona urbana do M unicípio.

$\S 1$ ㅇ Para os efeitos deste imposto, entende-se como zona urbana a definida em lei municipal, observado o requisito mínimo da existência de melhoramentos indicados em pelo menos dois dos incisos seguintes, construídos ou mantidos pelo Poder Público:

I - meio-frio ou calçamento, com canalização de águas pluviais; 


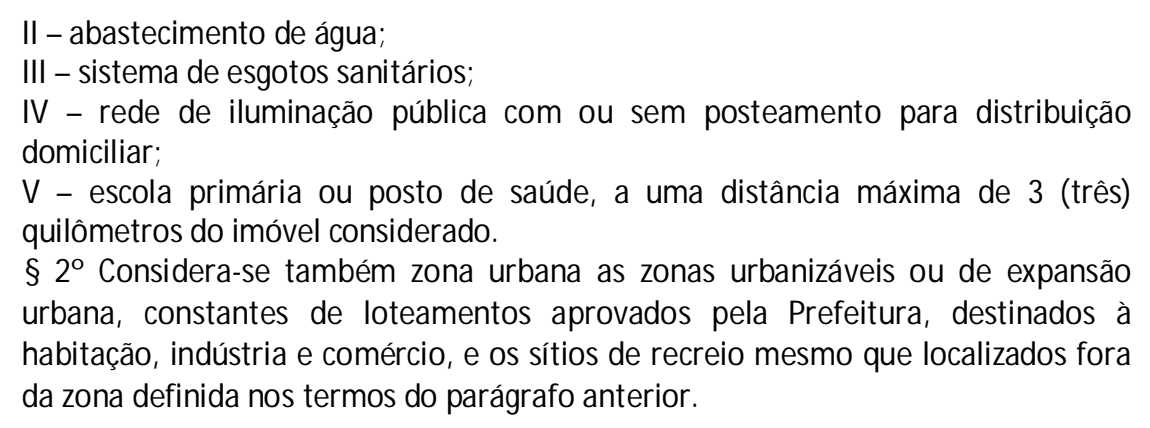

Examinando o dispositivo legal acima transcrito, observa-se que se fez quase uma cópia do artigo 32 do Código Tributário Nacional, sendo que as únicas diferenças que se notam são: 1) o fato de a lei municipal considerar como imóvel passível de ser cobrado IPTU o localizado na zona urbana, construído ou não; e 2) o fato de a lei municipal utilizar-se da prerrogativa do M unicípio descrita do $§ 2^{\circ}$ do artigo 32 do Código Tributário Nacional - qual seja, a de considerar como zona urbana as zonas urbanizáveis e as zonas de expansão urbana -, sendo as constantes de loteamentos aprovados pela Prefeitura - os quais devem ser destinados à moradia, indústria e comércio -, bem como os sítios de lazer, mesmo que localizados fora da zona urbana.

\section{0 conflito entre o IPTU e o ITR}

Como um interessante tema para discussão quanto ao critério especial do IPTU, tem-se o conflito entre este e o Imposto sobre a Propriedade Territorial Rural - ITR.

Repise-se que tal conflito é apenas relacionado ao critério espacial, nada tendo a ver com o critério pessoal da relação jurídica tributária, já que a competência para tributar o ITR é da União, enquanto que para o IPTU é do Município.

Primeiramente, verifica-se que adotado o conceito geográfico do que vem a ser zona urbana, o conceito de zona rural vem resultado por exclusão. Todavia, tais definições legais, mesmo que satisfatórias teoricamente, não afastam a incidência de alguns problemas práticos.

Segundo aponta Kiyoshi Harada, o primeiro conflito que se estende entre os dois tributos referidos é com relação à ausência de um claro e objetivo marco divisor dos limites do Município, sendo que isso foi objeto de uma grande disputa de tributação entre o Município de São Paulo e o M unicípio de Diadema (HARADA, 2008, p. 03). 
Em razão da falta de nitidez do mapa do estado de São Paulo, vários imóveis situados nas fronteiras entre os dois Municípios acima mencionados vinham sendo tributados pelos dois fiscos, ocorrendo, então, bitributação, que é fato inconstitucional.

Com o fim de solucionar esse problema, em 1989 foi elaborado e sugerido um convênio entre São Paulo e Diadema, substituindo o critério vago e impreciso vigente quanto aos limites desses dois Municípios, por outro mais definido, que redesenhava as divisórias litigiosas. No entanto, em que pese aprovado pela Câmara Municipal de São Paulo, o projeto foi recusado pela Câmara Municipal de Diadema, já que esta perderia algo em torno de 350 metros quadrados de seu território (HARADA, 2008, p. 03).

Um segundo problema que se constata é no concernente à tributação de uma área urbana cultivada, normalmente de hortaliças que servem para a subsistência da população.

Isso ocorreu em decorrência da constante e progressiva urbanização dos M unicípios, que empurrou os moradores de zonas rurais para locais cada vez mais distantes das zonas urbanas. Contudo, nem todos os agricultores deixaram sua terra diante da expansão urbana, razão pela qual deixaram de pagar ITR para pagar IPTU, o qual tem valor muito mais elevado (HARADA, 2008, p. 04).

Entretanto, observa-se que não é em todos os casos que o problema da substituição do ITR pelo IPTU é de ordem jurídica, mas sim que o nascimento do conflito maior se dá a partir do momento em que a questão sai dos limites da esfera jurídica, quando, por exemplo, o imóvel em que as hortaliças estão sendo cultivadas se enquadra no artigo 32, $\S 1^{\circ}$, do CTN. Nesse momento, surge um problema de política tributária ou urbana, não uma questão controvertida de Direito Tributário, posto que deve-se estabelecer, atentando-se à cada situação concreta apresentada, se o imóvel a ser tributado pertence á área urbana ou rural, considerando também o princípio da isonomia, com o escopo de tratar os iguais de forma igual e os desiguais de acordo com suas desigualdades.

Neste ponto, vale ressaltar que a norma descrita no $§ 10$ do artigo 32 do Código Tributário Nacional não é auto-aplicável, ou seja, não basta que o imóvel/local esteja enquadrado no dispositivo legal supramencionado, mas também que a lei municipal assim a declare. Assim, entende-se que se a lei municipal não declarar como de zona urbana determinada área destinada a prática da agropecuária, esta será atingida pelo ITR e não pelo IPTU, o qual é mais oneroso para o contribuinte (HARADA, 2008, p. 04). 
De outro vértice, importante salientar que não há nenhum impedimento para que a lei municipal conceda isenção ou redução da base de cálculo ou alíquota para o imóvel declarado como de zona urbana desrespeitando zona rural tradicional. É dessa faculdade que vem se utilizando os Municípios que enfrentam um processo de urbanização rápido e gradual.

Importante salientar, por fim, que a lei municipal pode excluir as propriedades de zona urbana onde é exercida a agropecuária da definição de zona urbana, assim como pode outorgar às mesmas incentivos fiscais e também descontos especiais se estiverem sob a incidência do IPTU; porém, se contrariar a política urbana do M unicípio, as áreas de cultivo localizadas nas zonas urbanas poderão ser desapropriadas, mediante o pagamento de justa indenização.

\section{Análise jurisprudencial}

Diante do exposto, após a análise devida dos tributos em questão, passa-se à discussão acerca dos hodiernos entendimentos vigentes perante os tribunais brasileiros.

De antemão, possível já é afirmar que tanto os tribunais estaduais como as supremas cortes, principalmente o Superior Tribunal de Justiça (STJ), vêm firmando posicionamento no sentido de colocar de lado o critério de localização do imóvel para dar destaque ao critério da destinação econômica que o mesmo possui.

A princípio pareceria, portanto, que o critério adotado pela legislação, para se definir a respeito da incidência dos impostos em questão seria o da localização e não 0 da destinação do imóvel.

Entretanto, as significativas alterações introduzidas pelo artigo 15, do Decreto-lei n. 57/66, acabaram por excluir do conceito fiscal de imóvel urbano aqueles que, embora situados em zona comprovadamente urbana, servissem para a exploração de atividade agrícola e pecuária, entre outras, sobre os quais incide o Imposto Territorial Rural-ITR, de competência da União. Segue o mesmo:

Art. 15. 0 disposto no art. 32 da Lei no 5.172, de 25 de outubro de 1966, não abrange o imóvel de que, comprovadamente, seja utilizado em exploração extrativa vegetal, agrícola, pecuária ou agro-industrial, incidindo assim, sobre 0 mesmo, o ITR e demais tributos com o mesmo cobrados. 
Ainda que tal dispositivo tenha sido revogado pelo art. 60, da Lei $n .05868 / 72$, este último dispositivo legal foi declarado inconstitucional pelo STF (RE 93.850-MG), diante da impossibilidade de que o CTN fosse modificado via lei complementar.

Sendo assim, restaram revigoradas as disposições do mencionado Decreto-Lei $57 / 66^{2}$.

O Supremo Tribunal Federal, em acórdão de que foi Relator o eminente Ministro XAVIER DE ALBUQUERQUE, no R.E. n. 76.057 (RTJ 70/479) (fls. 111 destes autos), decidiu:

Imposto territorial urbano. Não incide sobre imóvel utilizado na exploração agropastoril, ainda que situado nos limites da zona urbana, definida em lei municipal. Negação de vigência, pelas instâncias ordinárias, ao art. 15 do DL 57, de 18.11.66, modificador da norma contida no art. 32 do Código Tributário Nacional. Recurso extraordinário conhecido e provido. (Plenário, Rel. Min. Sidney Sanches, DJ de 4.6.1999).

Verifica-se, pois, que o critério adotado para tributar os imóveis localizados na zona urbana passou a ser o da sua destinação econômica. Assim, desde então, o Superior Tribunal de Justiça vem decidindo em consonância com o entendimento esposado pela Suprema Corte.

Algumas recentes decisões:

TRIBUTÁRIO. IPTU. ITR. FATO GERADOR. IMÓVEL SITUADO NA ZONA URBANA. LOCALIZAÇÃO. DESTINAÇÃO. CTN, ART. 32. DECRETO-LEI N. 57/66. VIGÊNCIA.

1. Ao ser promulgado, o Código Tributário Nacional valeu-se do critério topográfico para delimitar o fato gerador do Imposto sobre a Propriedade Predial e Territorial Urbana (IPTU) e o Imposto sobre a Propriedade Territorial Rural (ITR): se o imóvel estivesse situado na zona urbana, incidiria o IPTU; se na zona rural, incidiria o ITR.

2. Antes mesmo da entrada em vigor do CTN, o Decreto-Lei no 57/66 alterou esse critério, estabelecendo estarem sujeitos à incidência do ITR os imóveis situados na zona rural quando utilizados em exploração vegetal, agrícola, pecuária ou agroindustrial.

A jurisprudência reconheceu validade ao DL 57/66, o qual, assim como o CTN, passou a ter o status de lei complementar em face da superveniente Constituição de 1967. Assim, o critério topográfico previsto no art. 32 do CTN deve ser analisado em face do comando do art. 15 do DL 57/66, de modo que não incide o IPTU quando 0 imóvel situado na zona urbana receber quaisquer das destinações previstas 4. Recurso especial provido. (ST). REsp 492.869/PR, 1a Turma, Rel. Min. Teori Albino Zavascki, DJ de 7.3.2005).

TRIBUTÁRIO. IPTU E ITR. INCIDÊNCIA. INSUFICIÊNCIA DO CRITÉRIO DA LOCALIZAÇÃO DO IMÓVEL. NECESSIDADE DE SE OBSERVAR, TAMBÉM, A DESTINAÇÃO DO IMÓVEL.

2 Lembre-se que referido Decreto-Lei modificou o CTN, eis que, somente a partir da Constituição Federal de 1967 previu-se a necessidade de Lei Complementar para reger matéria tributária. 
- O critério da localização do imóvel é insuficiente para que se decida sobre a incidência do IPTU ou ITR, sendo necessário observar-se o critério da destinação econômica, conforme já decidiu a Egrégia 2a Turma, comDocumento: 3361920 RELATÓRIO E VOTO. Superior Tribunal de Justiça. base em posicionamento do STF sobre a vigência do $\mathrm{DL} \mathrm{n}$ 0 57/66. - Agravo regimental improvido. (STJ. AgRg no Ag 498.512/RS, 2a Turma, Rel. M in. Francisco Peçanha Martins, DJ de 16.5.2005).

Processo REsp 1027775 / SP. RECURSO ESPECIAL. 2008/0019250-4. Relator(a) Ministro CASTRO MEIRA (1125) . Órgão Julgador T2 - SEGUNDA TURMA. Data do Julgamento. 07/08/2008. Data da Publicação/Fonte DJe 04/09/2008

PROCESSUAL CIVIL E TRIBUTÁRIO. ART. 535 DO CPC. OM ISSÃO. INEXISTÊNCIA. IPTU. IMÓVEL SITUADO NA ZONA URBANA. CRITÉRIO DA DESTINAÇÃO ECONÔMICA. NECESSIDADE DE COM PROVAÇÃO. REEXAM E DE FATOSE PROVAS. SÚMULA 7/ST].

1. Não viola 0 artigo 535 do CPC nem importa negativa de prestação jurisdicional 0 acórdão que, mesmo sem ter examinado individualmente cada um dos argumentos trazidos pelo vencido, adotou fundamentação suficiente para decidir de modo integral a controvérsia.

2. 0 critério da localização do imóvel é insuficiente para que se decida sobre a incidência do IPTU ou ITR, sendo necessário observar-se o critério da destinação econômica. Entretanto é impossível, sem revolver s provas e fatos dos autos, infirmar a premissa consignada pelo aresto recorrido de que o imóvel não é utilizado para exploração agrícola e pecuária. Incidência da Súmula 7/STJ.

3. Recurso especial conhecido em parte e não provido.

0 Tribunal de Justiça do Estado do Paraná segue a mesma linha:

APELAÇÃO CÍVEL - DIREITO TRIBUTÁRIO - AÇÃO ANULATÓRIA DE LANÇAMENTO FISCAL - DIVERGÊNCIA SOBRE O ENQUADRAM ENTO DO IM ÓVEL COMO URBANO OU RURAL - CRITÉRIO DA DESTINAÇÃO - IM ÓVEL UTILIZADO PARA EXPLORAÇÃO AGRO-PASTORIL - COMPROVAÇÃO ATRAVÉS DE NOTAS FISCAIS DE PRODUTOR RURAL - INCIDÊNCIA DO IM POSTO TERRITORIAL RURAL - ART. 15, DO DEC. LEI № 57/66 - EXCLUSÃO DO IPTU - PRECEDENTES - SENTENÇA REFORM ADA- RECURSO PROVIDO. (...)." (Tribunal de Justiça do Paraná. Apelação Cível no-444.068-8 - 3a Câmara Cível - Rel. Des. Celso Rotoli de Macedo - DJ. 28/04/2008).

TRIBUTÁRIO. IPTU. EMBARGOS DE TERCEIRO. IPTU. ENQUADRAMENTO DO IM ÓVEL COMO URBANO OU RURAL, PARA FINS DE TRIBUTAÇÃO. CRITÉRIO DA DESTINAÇÃO. PREVALÊNCIA. PRECEDENTES. COMPROVAÇÃO QUE O IMÓVEL É UTILIZADO PARA EXPLORAÇÃO AGRO-PASTORIL. RECOLHIMENTO DE ITR. AFASTAMENTO DO IPTU QUE SE IMPÕE. RECURSO CONHECIDO. NÃO PROVIM ENTO. SENTENÇA MANTIDA. 1. De acordo com a jurisprudência atual, 0 critério da destinação é válido para distinguir um imóvel urbano do rural, para fins de tributação, pois nem sempre o critério geográfico é suficiente enquadrar corretamente um imóvel nas concepções de área urbana ou rural. 2. Tratando-se de imóvel de atividade preponderantemente rural, não há que se cogitar em exigência do IPTU, mas tão somente de ITR, inclusive a fim de evitar a bitributação." (Tribunal de Justiça do Paraná. Apelação Cível n.o 263271-5, 3a Câmara Cível, Rel. Des. Paulo Habith, DJ de 11/10/2007).

Assim, tem-se que não restam dúvidas quanto a aplicação dos critérios a serem utilizados quando da verificação acerca da incidência do imposto municipal ou federal. 0 critério da localização resta insuficiente devendo, necessariamente, levar-se em conta o fim para o qual o imóvel objeto do imposto é destinado. 


\section{Conclusão}

Não há dúvidas, portanto, que prevalece na legislação a opção pelo critério de destinação da área para distinguir os casos de incidência do IPTU em relação ao ITR. Pode-se até questionar o critério adotado, mas não há como substituir a opção do legislador pela do Julgador, sob pena de indevida intromissão nas atribuições de outro Poder.

Tal requisito da natureza da utilização, ou da função social da propriedade no momento da incidência, é compreensível na medida em que, de outro modo, o Município poderia declarar urbana toda e qualquer área, para o fim exclusivo de arrecadar IPTU, em evidente prejuízo à União, relativamente ao ITR (CF, art. 153, VI).

Os requisitos à propriedade ser urbana foram estabelecidos pelos $\S \S 10$ e $2^{\circ}$ do art. 32 da Lei 5.172/66, que, como já dito, passou a status de Lei Complementar. Ou seja, por certo, cumpre ponderar que, o disposto no artigo 32, do Código Tributário Nacional, assim, não abrangerá o imóvel que, muito embora venha a ser localizado dentro da zona urbana determinada pela municipalidade, seja comprovadamente utilizado em atividade agrícola.

Com efeito, levando-se em conta que a jurisprudência da maioria dos tribunais brasileiros é dominante no sentido de que se aplica o critério da destinação do imóvel para efeitos de incidência tributária, pode-se entender que, após a evolução normativa aqui explanada, os aplicadores do direito - aqui incluídos legisladores, julgadores e demais atividades vinculadas ao direito - finalmente parecem ter firmado tal entendimento.

Com isso, tanto o IPTU pode incidir em área rural quanto o ITR em área urbana, apenas que, tratando-se de situações excepcionais, exige-se prova de que o imóvel exerce destinação rural, apesar de urbano, ou que exerce destinação urbana, apesar de rural.

\section{Referências}

CARVALHO, Paulo de Barros. Curso de direito tributário. 19. ed. rev. São Paulo: Saraiva, 2007. COELHO, Werner Nabiça. IPTU, zona urbana e alíquotas perante o sistema federativo e a Emenda Constitucional n. 29/2000. Disponível em: «ttp://www.fiscosoft.com.br/main_index.php?home=home_artigos $\& \mathrm{~m}=\_\& n x \_=\&$ viewid $=1$ 09388>. Acesso em: 01 out. 2008.

HARADA, Kiyoshi. Imóvel cultivado em zona urbana. IPTU, ITR ou incentivo fiscal?. Disponível em: ঝttp://jus2.uol.com.br/doutrina/texto.asp?id=10223>. Acesso em: 01 out. 2008. 
M ACHADO, Hugo de Brito. Curso de Direito Tributário. 23. ed., São Paulo: Malheiros, 2004.

M ARTINS, Ives Gandra da Silva, et al. Curso de Direito Tributário. 8a Ed. São Paulo: Saraiva, 2001.

M ELLO, Celso Antônio Bandeira de. Curso de direito administrativo. 12. ed. rev. atual. e ampl. São Paulo: M alheiros, 2000.

M IRANDA DE CARVALHO, Rubens. Contribuição de M elhoria e Taxas no Direito Brasileiro. São Paulo: Juarez de Oliveira, 1999.

VILLAÇA, Sérgio. 0 plano diretor e a lei do perímetro urbano. Disponível em: বhttp://www.cebi.com.br/boletim/boletim_23/editorial.htm>. Acesso em: 01 out. 2008. 